www.jmscr.igmpublication.org

Index Copernicus Value: 79.54

ISSN (e)-2347-176x ISSN (p) 2455-0450

crossref DOI: https://dx.doi.org/10.18535/jmscr/v7i5.142

Journal Of Medical Science And Clinical Research

\title{
Anterior abdominal wall Metastasis of Squamous Cell Carcinoma of tongue - A Case Report
}

\author{
Authors \\ Yadav R.K.*, Singh A., Prasad S.N., Verma S., Kumar N \\ Department of Radiation Oncology, J.K. Cancer Institute, Kanpur, India \\ *Correspondence Author \\ Yadav Raj Kumar \\ Department of Radiation Oncology, J.K. Cancer Institute, Rawatpur main road, Kanpur, \\ Uttar Pradesh, India (208002)
}

\begin{abstract}
Cancer of the oral cavity makes up approximately $30 \%$ of all head and neck region tumors. Skin metastasis usually occurs in the face and neck i.e near primary site. It's very rare to metastasis to anterior abdominal wall from carcinoma of tongue. We reported a case of carcinoma tongue, post total glossectomy and bilateral neck dissection followed by adjuvant EBRT (External beam radiotherapy) with concurrent chemotherapy (inj. Cisplatin) presented with Recurrent metastasic lesion at anterior abdominal wall along with bilateral lung metastasis.

Keywords: anterior abdominal wall recurrence, carcinoma tongue, total glossectomy, EBRT.
\end{abstract}

\section{Introduction}

Cancer of the oral cavity makes up approximately $30 \%$ of all head and neck region tumors. Skin metastasis is rare with an incidence ranging between $0.7 \%$ and $2.4 \%$. Skin metastasis usually occurs in the neck, scalp, and over the skin near the primary site $^{[1]}$. The most common mode of spread of SCCHN (Squamous cell carcinoma of Head and Neck) is via regional lymph nodes to the cervical drainage areas ${ }^{[2]}$. Other lymph node groups are rarely involved. Patients suffering from a squamous cell carcinoma (SCC) of the head and neck region with distant metastases generally have a very poor prognosis ${ }^{[3]}$. Moriya et al. (2004) recently reported on a patient suffering from a cardial metastasis of an oral SSC together with additional metastases in the liver, lung, spleen and kidneys $^{[4]}$. Distant metastasis in the gluteal muscle of a 65-year-old patient suffering from a SSC of the larynx has been recently described $^{[5]}$. Oo et al. (2004) have identified three patients with metastases in the axillary lymph nodes over a period of 20 years $^{[6)}$. Mess et al. (1986) have reported on distant metastases which were localized in the carpal bones of the midhand and in the bones of the foot $^{[7]}$. As per our knowledge, no case has been reported $\mathrm{u}$ to date on the manifestation of distant metastases of a SCC in the soft tissue of the anterior abdominal wall till now in the literature . Distant metastases to lung, liver and bone are via haematogeneous spread. Cutaneous metastas is are associated with poor 
prognosis and advanced disease ${ }^{[8]}$. Distant metastasis of squamous cell carcinoma of tongue in peripheral skeletal muscle and adjacent soft tissue also reported by Ralf Smeets et al(2008). ${ }^{[9]}$. We report a case of carcinoma tongue, post total glossectomy and post EBRT and chemotherapy

Table 1: Survey of the literature

\begin{tabular}{|c|c|}
\hline Authors & Cases \\
\hline Probert et al. 1974 [24] & 96 Patients with $S C C, 31 \%$ OSCC \\
\hline Merino et al. 1977 [25] & 546 patients withSCC, $21 \% \mathrm{OSCC}$ \\
\hline Papacet al. 1984 [26] & $\begin{array}{l}52 \text { patients with } \mathrm{CCC}, 4 \% \text { at the bottom } \\
\text { of the oral cavity, } 10 \% \text { tumors of the } \\
\text { tongue }\end{array}$ \\
\hline Troell et a1. 1995 [27] & $\begin{array}{l}79 \text { patients w ith SCC with a total of } 145 \\
\text { remote metastases. }\end{array}$ \\
\hline De Bree et al. $2000[28]$ & 17 patients with SCC, $34 \% \mathrm{OSCC}$ \\
\hline Leon et al. 2000 [29] & 64 patients withSCC, $2 \% \mathrm{OSCC}$ \\
\hline
\end{tabular}

\section{Case Report}

54 year old man presented in our OPD on 27/10/17 with history of ulceroproliferative mass lesion on right lateral tongue which crosses midline. size was about $3 \times 3 \mathrm{~cm}$.who underwent proper examination and investigation . On biopsy report it was moderately differentiated squmous cell carcinoma. Patient underwent total glossectomy and bilateral neck dissection on December 17. As per histopath report it was moderately differentiated squmous cell carcinoma with contralatral one neck node positive. Patient received EBRT $64 \mathrm{GY}$ in 32 fraction with concurrent injection cisplatin $50 \mathrm{mg}$ weekly and received 3cycle injection cis-platin. After one month of follow up patient complained right iliac fossa pain. On examination there was hard, irregular, right iliac fossa mass with multiple bilateral inguinal lymph node, largest one is $1.5 \mathrm{x}$ $1.5 \mathrm{~cm}$, hard mobile. On FNAC of right iliac fossa mass on $24 / 04 / 18$, it was metastatic squmous cell carcinoma. On PET-CECT report (8 may 18) total glossectomy status. No focal abnormal FDG avid presented with anterior abdominal wall mass lesion and bilateral inguinal lymphadenopathy along with bilateral lung metastasis. Furthermore, we show an overview on the current literature on metastases originating from head and neck tumors [Table 1]. lung $65 \%$, bone $25 \%$, liver $24 \%$, skin $14 \%$, brain $13 \%$, adrena $18 \%$, heart $7 \%$, kidney $6 \%$, peritoneum, mediastinum and soft tissue each $5 \%$, esophag us $4 \%$, spleen $3 \%$, bone marrow $3 \%$, thyroid $2 \%$, prostate $1 \%$ and middle ear $1 \%$.

primary tumor orally or in the oropharynx: $1 \mathrm{ung} 52 \%$, bone $20.3 \%$, liver $6 \%$, mediastinum $2.9 \%$, lung and bone $3.3 \%$ and others $15.4 \%$. Primary tumor in the nasopharynx: bone $54 \%$, bng $23.8 \%$, primary tumors of the fossa tonsillaris and of the basis of the tongue: metastases were primarily found in the liver $(22 \%$ and $10.8 \%$ respectiveliy)

lung $75 \%$, bone $44 \%$, liver $17 \%$, skin $13 \%$, brain $13 \%$, adrenal $6 \%$, heart $8 \%$, kidney $10 \%$, GIT $15 \%$, medias tinum $10 \%$, spleen $3 \%$ and thyroid $6 \%$.

lung 45 , bone 27 , liver 11 , mediastinum 10 and other localis ations (adrenal, brain, pericard, lidney and thyroid) 7 . lung $71 \%$, mediastinum $24 \%$, bone $24 \%$ and liver $6 \%$.

lung/madiastimum $52 \%$, bone $12 \%$, liver $5 \%$, a combination oflung with bone and liver or skin $31 \%$. lesion is seen. No focal FDG avid lesion in bilateral neck. Multiple nodular lesion with central necrosis and some with cavitation are seen in both lung upper lobes, largest in left lung upper lobe 3.8 into $2.1 \mathrm{~cm}$, SUV max 6.7. soft tissue density mass lesion with increased FDG uptake and central necrosis is seen in right internal oblique muscle at lower lateral abdominal wall. Measuring $4 \times 2.4 \times 3.4 \mathrm{~cm}$, SUV max 11.4. In view of distant metastasis patient was planned for palliative chemotherapy in the form of injection cisplatin 50mg d1-d2 and injection 5-FU $1.5 \mathrm{mg}$ d1-d2, 3 weekly. After 3 cycle of palliative chemotherapy there was complete response at anterior abdominal muscle mass lesion and bilateral inguinal node. In view of lung metastasis and poor tolerability of patien further injectable chemotherapy withheld \& planned for oral tab Gefitinib $250 \mathrm{mg}$ once a day.

Patient was clinically normal at anterior abdominal wall but having lung mass in both upper lobe lung till the writing of this manuscript on 15/05/19 having a average general condition with KPS score of 80. 


\section{Discussion}

Pitman et al reported that the development of cutaneous metastases are more common if two or more cervical lymph nodes metastases are present or there is extracapsular spread of tumour in the cervical nodes ${ }^{[10]}$.

The occurrence of cutaneous metastases is associated with a very poor prognosis. Median survival from onset of cutaneous metastases ranges from three to seven months, with zero percent one year survival rate. The ${ }^{]}$Cutaneous metastases from SCCHN in contrast to other internal malignancies are rare and literature review indicates a much lower incidence of between $0.8-1.3$ percent $^{[8]}$.

Distant metastases commonly develop before, during, and after treatment for head and neck squamous cell carcinomas. The lungs were the most-frequent location of distant metastases in patients with oral cavity can cer (54.3\%), oropharyngeal cancer $(50.0 \%)$, and hypopharyngeal cancer $(60.5 \%)$. Bone $(57.6 \%)$ was the most co mmon site of metastasis in patients with Nasopharyngeal carcinoma, while laryngeal cancer tended to metastasiz e to the liver $(80 \%)^{[2]}$.

Cologlu et al reported that the pulmonary circulation can possibly be bypassed via the azygous and vertebral venous systems and Batson's plexus therefore allowing for skin implantations. They have also reported that tumour cells may survive the filtration process of the pulmonary circulation and thus metastasize to distant skin sites. ${ }^{[6]}$ therefore allowing for skin implantations. They have also reported that tumour cells may survive the filtration process of the pulmonary circulation and thus metastasize to distant skin sites. ${ }^{(12)}$

Histologically, cutaneous metastases are distinguished from primary cutaneous squamous cell carcinom as by the presence of a heavy dermal component that has no connection with the epidermis. There may be associated necrosis, inflammation and lymphovascular invasion ${ }^{[11]}$.

The occurrence of cutaneous metastases is associated with a very poor prognosis. Median survival from onset of cutaneous metastases ranges from three to seven months, with zero percent one year survival rate ${ }^{[1]}$.

Treatment is palliative and surgical excision, radiotherapy and chemotherapy have all been used depen ding on the clinical circumstances ${ }^{[8]}$. Berger and Fletcher ${ }^{[13]}$ in their study reported that length of survival was ap proximately 3 months after skin metastasis becomes clinically evident in HNSCC. The treatment intent is usually palliative with the available options being surgical excision, chemotherapy, External beam radiotherapy or a combination of these. It has recently been reported that some patients who suffered an untreated SCC of the head and neck region survived for more than five years. Studies in which the outcome of patients with a SCC who were not treated at all were compared to the outcome of patients who underwent a palliative therapy showed that the mean survival rate was 8.4 months larger in patients who underwent a palliative therapy ${ }^{[14]}$. However, other authors reported on prolonged surviving rates in some cases of untreated tumors of the head and neck [15,16,17,18]. Kowalski and Carvalho (2000, 2001) analyzed in a long-lasting retrospective study from 1953 to 1990 the clinical outcome of 808 patients with an untreated tumor of the head and neck [19, 20]. They reported that, in accordance with the above findings, patients, who did not receive any treatment, survived up to 4 years ${ }^{[21]}$.

\section{Conclusion}

Anterior abdominal wall metastasis from HNSCC is hardly reported in literature. The appearance of new anterior abdominal wall lesions in patients of HNSCC mandates a vigilant history and thorough physical examination. All such lesions should be viewed with a high index of suspicion.

\section{References}

1. Shashank Srinivasan, Nitin Leekha, Sweety Gupta, Umang Mithal, Vandana Arora, Sudarsan De Distant skin metastases from carcinoma buccal mucosa: A rare presentation 
E-IJD case report 2016, Vol 61, Issue 4:468

2. Distant Metastases of Head and Neck Squamous Cell Carcinomas - Experience from Eastern Taiwan Lee-Ping Hsu, PeirRong Chen Department of Otorhinolaryngology, Buddhist Tzu Chi General Hospital, Hualien, Taiwan Tzu Chi Med J 2005; 17:99-104)

3. Rao DN, Shroff PD, Chattopadhyay G, Dinshaw KA: Survival anal- ysis of 5595 head and neck cancers - results of conventional treatment in a high-risk population. Br J Cancer 1998, 77:1514-1518.

4. Moriya J, Daimon Y, Itoh Y, Nakano M, Yamada Z: Vegetative car- diac metastases of oral cavity cancer: an autopsy case report. $J$ Cardiol 2004, 44:33-38.

5. Marioni G, Blandamura S, Calgaro N, Ferraro SM, Stramare R, Staffieri A, De Filippis C: Distant muscular (gluteus maximus muscle) metastasis from laryngeal squamous cell carcinoma. Acta Otolaryngol 2005, 125:678-682.

6. Oo AL, Yamaguchi S, Iwaki H, Amagasa T: Axillary nodal metasta- sis from oral and maxillofacial cancers: a report of 3 cases. $J$ Oral Maxillofac Surg 2004, 62:1019-1024.

7. Mess D, Songer M: Head and neck carcinoma metastases to the hand and foot. A case report of simultaneous involve- ment. Orthopedics 1986, 9:975-977.

8. Cutaneous Metastases from Head and Neck Squamous Cell Carcinoma Sangeetha Poovaneswaran, FRCR (UK), Vinidh Paleri, FRCS (ORL-HNS), Fraser Charlton, FRCPath (UK), Werner Dobrowsky, FRCR, Charles Kelly, FRCR (UK) Med J Malaysia Vol 67 No 4 August 2012

9. Ralf Smeets, Mauria B Grosjean, Max Heiland, Dieter Riediger, and Oliver Maciejewski: Distant metastasis of squamous cell carcinoma of tongue in peripheral skeletal muscle and adjacent soft tissue.2008:article/10.1186/1786-160×-4-7.

10. Pitman KT, John son JT. Skin metastases from head and neck squamous cell carcinoma: incidence and impact. Head Neck. 1999;21:560 -565.

11. Yoskovitch A, Hier MP, Okrainec A, Black MJ, Rochon L. Skin metastases in squamous cell carcinoma of the head and neck. Otolaryngol Head Neck Surg 2001;124:248-5

12. Caloglu M, Uygun K, Altaner S, Uzal C, Kocak Z, Piskin S. Nasopharyngeal carcinoma with extensive nodular skin metastases: A case report. Tumori 2006; 92: 181-4

13. Berger DS, Fletcher GH. Distant metastases following local control of squamous cell carcinoma of the nasopharynx, tonsillar fossa and base of the tongue. Radiology 1971;100;141-3.

14. Burns L, Chase D, Goodwin WJ: Treatment of patients with stage IV cancer: do the ends justify the means?. Otolaryngol Head Neck Surg. 1987, 97: 8-14.

15. Shimkin MB: Duration of life in untreated cancer. Cancer. 1951, 4: 1-8. 10.1002/10970142(195101)4:1<1::AID-

CNCR2820040103>3.0.CO;2-R.

16. Shimkin MB, Griswold MH, Cutler SJ: Classics in oncology. Survival in untreated and treated cancer. CA Cancer J Clin. 1984, 34: 282-294.

17. Stell PM: Survival times in end-stage head and neck cancer. Eur J Surg Oncol. 1989, 15: 407-410.

18. Welch CE, Nathanson IT: Life expectancy and incidence of malignant disease. II. Carcinoma of the lip, oral cavity, larynx and antrum. Am J Cancer. 1937, 31: 238-252.

19. Kowalski LP, Carvalho AL: Natural history of untreated head and neck cancer. Eur $\mathbf{J}$ Cancer. 2000, 36: 1032-1037. 10.1016/S0959-8049(00)00054-X.

20. Kowalski LP, Carvalho AL: Influence of time delay and clinical upstaging in the prognosis of head and neck cancer. Oral Oncol. 2001, 37: 94-98. 10.1016/S1368-8375(00)00066-X. 